\title{
ENVIRONMENTAL FIDELITY AND TIME AVERAGING — SOURCES OF APPARENT COMMUNITY STABILITY AND UNITY
}

\author{
BAMBACH*, Richard K., Department of Geological Sciences, Virginia \\ Polytechnic Institute and State University, Blacksburg, VA 24061, U. S. A.; \\ BENNINGTON, J Bret, Department of Geology, 114 Hofstra University, \\ Hempstead, NY 11550, U. S. A.
}

In Paleozoic marine settings particular paleocommunity types recur whenever facies recording the same environmental conditions recur. This pattern is observed in Ordovician, Silurian, Devonian, and Carboniferous units in both North America and Europe. Paleocommunity recurrence has led to the concepts of environmental tracking, coordinated stasis, and community stability and has been used to argue that community unity in the fossil record was generated by biological interactions. In contrast, many neontologists doubt that there is any significant integration or stabilizing interactive structure in most Recent level-bottom marine communities. Likewise, the autecologies of members of particular Paleozoic communities do not indicate any great potential for forming elaborate interactive community structures either. If this is so, then why should such loosely organized ecological systems appear to be stable entities in the geologic record? Why should similar paleocommunity types appear to persist for millions of years with little apparent change? We suggest that the apparent stability of paleocommunity types is produced by the continuity of conditions characterizing particular habitats, not by biological interaction. The physical parameters of a particular type of habitat do not alter over time (a touchstone of actualism). Organisms well adapted to particular conditions will recur whenever they have access to habitats characterized by those conditions. Hence the environmental fidelity of many marine fossil assemblages and their persistence in time. In fact, statistical analysis reveals that although similar assemblages do occur when the same environmental conditions recur, the similarity between assemblages decreases over both space and time.

Patterns of paleocommunity recurrence have also been used to argue that marine communities are discrete entities rather than just arbitrarily defined segments of a community gradient. Using fossil assemblages to infer pattern in once-living communities is plagued not only by incomplete preservation but also by time-averaging. The median age of shells in many Recent sub-fossil assemblages is commonly more than a century. Time-averaging blurs the short-term and small scale patterns present in living communities (standing crop census, seasonal population change, habitat patches) and the scale at which any biological interactions actually occur. At the same time, it mixes specimens derived from shifting distinct local habitats to create more homogeneous large scale and long term patterns. Overall, time-averaging reduces variability and masks the biological entities that actually interacted in living assemblages. Fossil assemblages are not comparable to living assemblages and do not, indeed, can not preserve a resolvable record of the structure of the living community. Fossil assemblages may appear to display more similar patterns of species occurrence over time and space than are commonly observed in living assemblages, but this is a product of time-averaging, not biological interaction.

At present there is no reason to infer from the fossil record that biological interactions were maintaining community unity in the Paleozoic. Intervals of apparent community stability are to be expected simply because environmental conditions remained constant in particular habitats that recurred through time. What is of more interest are the short intervals over which new community patterns become established due to the rapid evolutionary turnover of previously persistent species groups. 